\title{
УПРАВЛЕНИЕ РИСКАМИ ПРИ ИНКОРПОРИРОВАНИИ МАЛОГО ИННОВАЦИОННОГО ПРЕДПРИНИМАТЕЛЬСТВА В ВЫСОКОТЕХНОЛОГИЧНОЕ ПРОИЗВОДСТВО
}

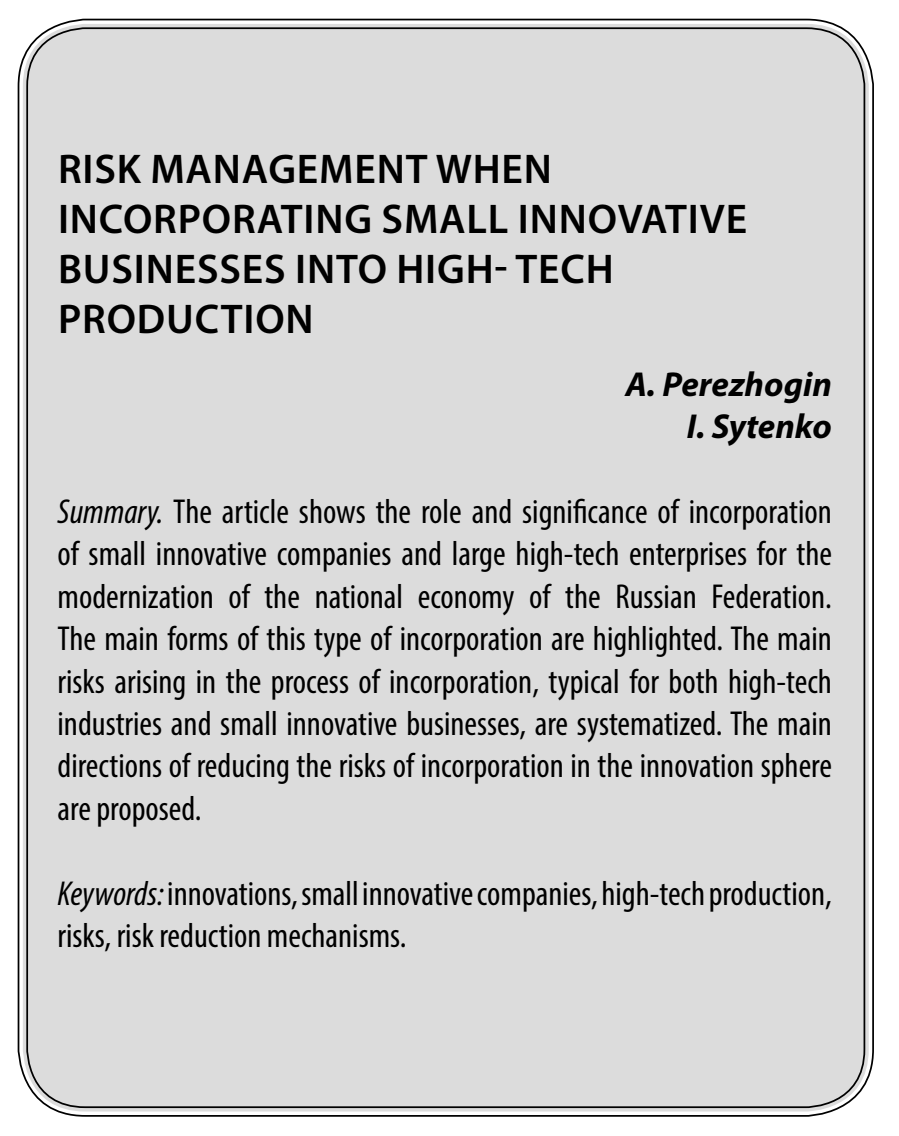

$\mathbf{0}$ беспечение эффективной модернизации отечественной экономики непосредственно зависит от результативности функционирования малых инновационных компаний в целом и качества их интеграции с высокотехнологичными организациями реального сектора экономической системы РФ, в частности. На необходимость содействия прогрессивному развитию малого инновационного бизнеса, в том числе стартапов, указывал, в частности, Президент РФ в рамках Послания Федеральному Собранию 2018 г. [2, с. 2]. Активизация использования результатов деятельности малых инновационных предприятий компаниями различных отраслей экономики РФ предусмотрена и положениями Стратегии пространственного развития национальной экономики до 2025 г. [1].

В целом, в 2011-2019 г.г. сектор малых инновационных предприятий в отечественной экономике развивался достаточно интенсивно. Как показано на рис. 1, об-
Пережогин Андрей Евгеньевич

Аспирант, Российская академия народного хозяйства и государственной службы при Президенте Российской Федерации (РАНХиГС) Sealman15@yandex.ru

Сытенко Илья Сергеевич

Аспирант, Российская академия народного хозяйства и государственной службы при Президенте Российской Федерачии (РАНХиГС)

Аннотация. В статье показаны роль и значение инкорпорирования малых инновационных компаний и крупных высокотехнологичных предприятий для модернизации национальной экономики РФ. Выделены основные формы такого рода инкорпорирования. Систематизированы основные риски, возникающие в процессе инкорпорирования, типичные как для высокотехнологичных производств, так и для малых субъектов инновационного предпринимательства. Предложены основные направления снижения рисков инкорпорирования в инновационной сфере.

Ключевые слова: инновации, малые инновационные компании, высокотехнологичные производства, риски, механизмы снижения рисков.

щий темп роста объема финансирования деятельности такого рода фирм за рассматриваемый период составил $326,7 \%$.

Вместе с тем, в 2018 г. общий уровень рентабельности промышленной продукции в РФ составил лишь 6,4\%, что на 2,3 процентных пункта ниже значения аналогичного показателя в 2011 г. [6, с. 529]. Это свидетельствует в том числе и о недостаточной интенсивности и эффективности механизмов интеграции высокотехнологичных компаний промышленности и малых инновационных предприятий, о недостаточном использовании в процессе реального производства передовых инновационных разработок, формируемых в том числе в секторе малых инновационных фирм и стартапов.

Инкорпорирование деятельности малых инновационных предприятий в высокотехнологичные производственные структуры представляет собой процесс 
Таблица 1. Основные риски, возникающие при инкорпорировании субъектов малого инновационного предпринимательства в деятельность крупных высокотехнологичных компаний (систематизировано автором)

\begin{tabular}{|c|c|}
\hline Риски для крупных высокотехнологичных компаний & Риски для малых инновационных предприятий \\
\hline $\begin{array}{l}\text { 1. Риск переоценки стоимости малой инновационной фирмы при } \\
\text { приобретении ее целиком или определенной доли в капитале. } \\
\text { 2. Сложность синхронизации технологических процессов } \\
\text { и стандартов управления между высокотехнологичной фирмой } \\
\text { и субъектом малого инновационного предпринимательства. } \\
\text { 3. Возможное не вполне корректное выполнение малой } \\
\text { инновационной фирмой своих договорных обязательств } \\
\text { по поставке инновационной продукции или оказанию услуг (при } \\
\text { договорной форме интеграции). }\end{array}$ & $\begin{array}{l}\text { 1. Риск целенаправленного занижения стоимости малой } \\
\text { инновационной фирмы или доли в ее капитале в процессе } \\
\text { рыночной сделки. } \\
\text { 2. Риски неоправданного, нерыночного давления } \\
\text { на экономическое поведение руководства малой инновационной } \\
\text { фирмы со стороны менеджмента крупной компании. } \\
\text { 3. Риск прямого враждебного поглощения потенциально } \\
\text { эффективной малой инновационной фирмы крупной } \\
\text { промышленной корпорацией. } \\
\text { 4. Риск не вполне корректной защиты интересов малой } \\
\text { инновационной фирмы в рамках судебной системы РФ. }\end{array}$ \\
\hline
\end{tabular}

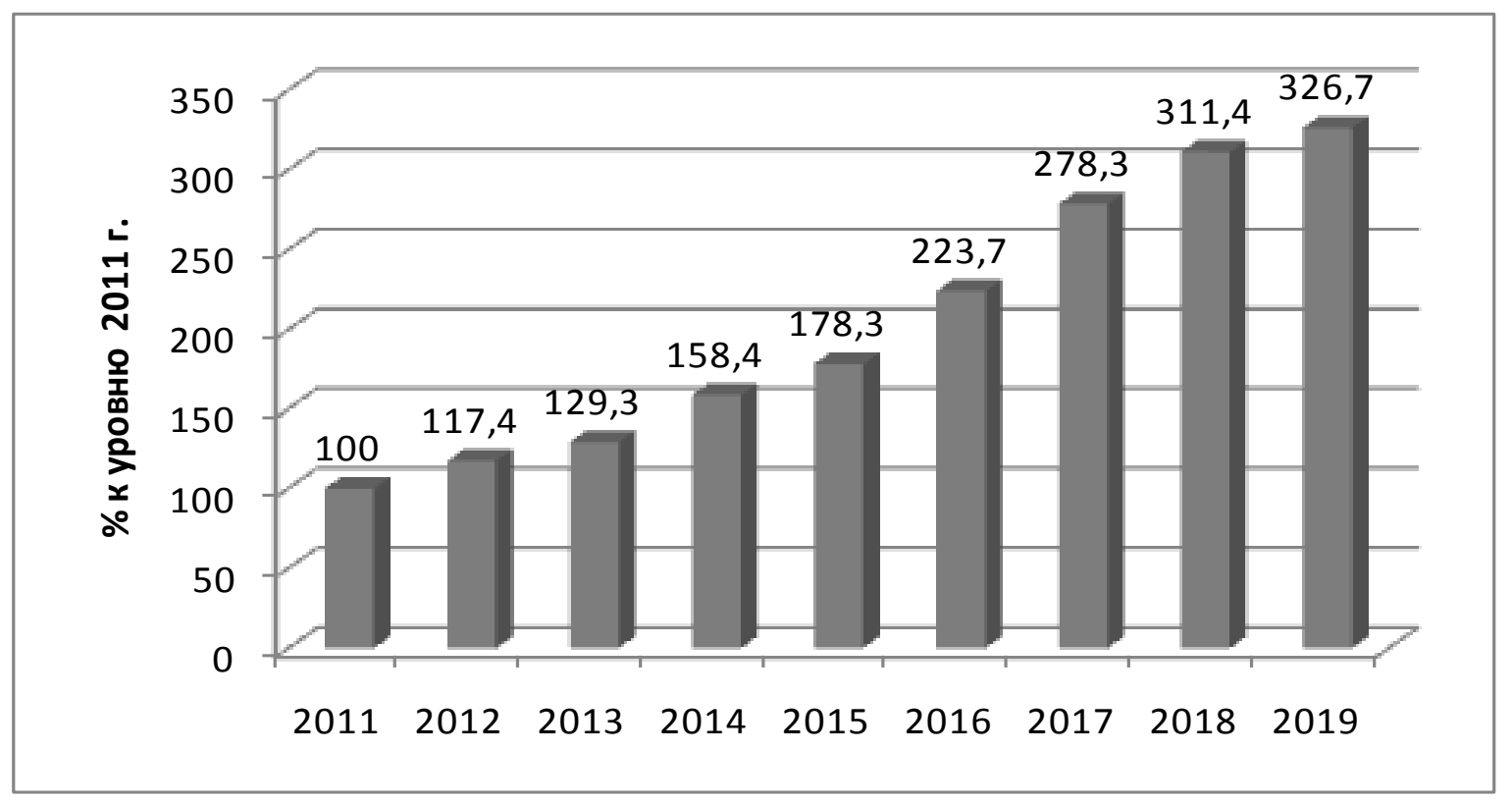

Рис. 1. Темпы роста объемов финансирования малых инновационных компаний в экономике РФ, $\%$ к 2011 г. [5, с. 238]

их долгосрочной устойчивой интеграции. Такого рода инкорпорирование может иметь следующие основные формы [4, с. 86]:

- приобретение крупной высокотехнологичной компанией инновационной фирмы в целом;

- покупка определенного, как правило контрольного, пакета акций (долей) в капитале малой инновационной компании;

- формирование долгосрочных договорных отношений между малым инновационным предприятием и крупной промышленной высокотехнологичной компанией относительно поставки инновационной продукции, оборудования, оказания услуг и т.п.;
- предоставление малой инновационной компании корпоративного займа со стороны крупного промышленного предприятия с возможностью последующей конвертации стоимости такого рода займа в долю в капитале субъекта малого инновационного предпринимательства.

Риски развития отношений между малой инновационной компанией и крупной высокотехнологичной структурой, соответственно, являются специфичными для различных форм инкорпорирования их бизнес-процессов. Вместе с тем, можно выделить некоторые общие группы финансово-экономических рисков такого рода (таблица 1). 
Как показано в таблице 1, возможные риски для собственников малых инновационных фирм в процессе инкорпорирования с крупными высокотехнологичными предприятиями в условиях РФ являются потенциально более существенными по сравнению с финансово-экономическими рисками последних. На риск недостаточно эффективной судебной защиты малых инновационных компаний в процессе возможных арбитражных споров указывает, в частности, И.М. Воробьева [3, с. 875]. Действительно, отечественные суды при рассмотрении такого рода исков обычно встают на сторону крупных субъектов хозяйствования. А. В. Якимов указывает также на достаточно значимые коррупционные риски в процессе организации и осуществления интеграционных взаимодействий между малыми инновационными компаниями и крупными высокотехнологичными производствами в экономике РФ [7, с. 56].

По нашему мнению, основными инструментами снижения выделенных основных рисков, возникающих в процессе инкорпорирования субъектов малого инновационного предпринимательства и высокотехнологичных производств, являются:

- изначальное вхождение в капитал малой инновационной фирмы в качестве миноритарного собственника крупной, влиятельной компании или государства, например в лице внебюджетных фондов поддержки инноваций федерального или регионального уровня, что позволит сбалансировать потенциальные интересы и фактические возможности в случае дальнейшего ин- корпорирования с крупными высокотехнологичными промышленными предприятиями;

- изначальное комплексное согласование технических и управленческих стандартов развития малой инновационной фирмы и потенциального крупного участника процесса инкорпорирования с тем, чтобы в последующем минимизировать риски технико-технологической дезинтеграции производственных процессов при объединении двух указанных организаций;

- страхование рисков, связанных с процессами инновационного инкорпорирования, в специализированных страховых организациях (следует отметить, что практика страхования такого рода рисков, как и предпринимательских рисков в целом, на страховом рынке РФ пока находится в зачаточном состоянии);

- максимально детальная проработка гражданско-правовых договоров, сопутствующих той или иной форме инкорпорирования деятельности малых инновационных компаний и крупных высокотехнологичных субъектов хозяйствования.

Кроме того, для определенного уменьшения рисков инкорпорирования необходимо формирование и обеспечение прогрессивного развития в РФ ассоциаций и союзов малых инновационных компаний, позволяющих согласованно защищать права и законные интересы последних, в том числе в процессе возможного их ущемления крупными субъектами хозяйствования в процессе корпоративной интеграции.

\section{ЛИТЕРАТУРА}

1. Стратегия пространственного развития Российской Федерации на период до 2025 г. // Утверждена Постановлением Правительства РФ от 13.02 .2019 № 209-р [Экономико-правовая база“Гаран"]. Режим доступа: свободный (дата обращения 21.03.2020).

2. Послание Президента Российской Федерации Федеральному Собранию 5 ноября 2018 г. // Российская газета._ 2018. — № 211.—C. 1-2.

3. Воробьева И. М. Проблемы создания и функционирования малых инновационных предприятий // Молодой ученый. — 2015.— № 11.— С. $784-787$.

4. Кристенсен К. Теория инноваций как инструмент предсказания отраслевых изменений. — М.: Альбина Паблишер, 2017. - 480 c.

5. Российская экономика: проблемы и перспективы.—М.: Из-во Института экономической политики, 2020. — 458 с.

6. Российский статистический ежегодник.—М.: Из-во Федеральной службы государственной статистики, 2019. — 824 с.

7. Якимов А. В. Проблемы взаимодействия малых инновационных компаний и инвесторов // Вестник экономики и менеджмента. - 2019. - № 11.— C. 54-57. 